\title{
Economic and social factors affecting the epidemiological process of the SARS-CoV-2 coronavirus
}

\section{S.V.Ponomarenko}

SophiGen, Germany

For contacts: Sophia Ponomarenko, e-mail: ponomarenko@t-online.de; Tel. (49) 1628491717

\begin{abstract}
Summary
Aim. Analyze the impact of several economic and social factors on the course of the COVID-19 pandemic, comparing the latest statistics in large and representative samples. Assess the factors inhibiting the negative consequences of the infectious process of the SARS-CoV-2 virus.
\end{abstract}

Materials and methods. To create this review, the required academic and media publications also statistical data were found on the Internet for the selected keywords, both for a single tag and in various combinations of them. Population statistics have been created on the base of data available on the Internet.

Results and discussion. The relationship between economic or social factors and the impacts of the 15-month COVID-19 pandemic in different regions was investigated using a variety of available statistics for five continents and 53 countries. A positive relationship was found between the consequences of the SARS-CoV-2 epidemic and GDP per capita or the type of human diet with correlation coefficients in the range of 0.48-0.87. The development of the viral epidemic demonstrates a less clear correlation on population density from $r=-0.68$ to $r=-0.16$, depending on the selected group of countries. For island nations, geographic isolation was the dominant defense against SARSCoV-2 infection.

Conclusions. An analytical and quantitative study of economic or social aspects and numerous statistics on the spread of the COVID-19 pandemic, carried out on large representative samples, showed that, the productive infection and pathogenicity of SARS-CoV-2, critically increase with an excessive amount of consumed proteins and fats. To successfully control of the progression COVID19 disease, the WHO guidelines for the amount of macronutrients consumed should be followed. This cost-effective approach will reduce health care expenditures in all countries during the epidemic.

KEYWORDS: coronavirus; COVID-19; SARS-CoV-2; epidemic, pandemic; pathogenesis, risk factors

Conflict of interest: The author declares that she has no commercial or non-profit associations that could cause a conflict of interest in connection with the published manuscript.

Abbreviations: WHO-World Health Organization, SARS-severe acute respiratory syndrome, RPr-rate of prevalence, IFR- infection fatality rate, sICs- single island countries, NA-Northern America, GDPGross Domestic Product per capita, CFR-case fatality rate. 


\section{Introduction}

A virus pandemic is an epidemic of a dangerous infectious disease that affects a huge number of people a lot of countries or worldwide. The WHO definition is: „A pandemic is the worldwide spread of a new disease" [1]. The new discovered in 2019 pathogenic coronavirus SARS-CoV-2 caused the disease alarming human community. The contagious grave disease was official named COVID-19 by WHO and pandemic of the highly transmissible by aerosol-generated particles disease was recognized on the 11 March 2020 [2].

Conclusions about the development of each epidemic are based on statistical data of the spreading infection in the population during termed period. Using these statistical data, models of the new epidemic process were assembled and a strategy or tactics to combat the pathogenic infection were developed [3-4].

Epidemiologists, virologists and clinicians analyze primarily the risks of a pandemic and their factors [5-12]. The results of intensive studies of the structure and function of SARS-CoV-2 coronavirus and COVID-19 disease expansion, carried out over the past year by researchers from the world community [13-14]. Huge number of results and conclusions concerning pandemic have been published in internet that should help in realizing of methods to stop virus SARS-CoV-2 reproduction.

The COVID-19 pandemic is a global burden process with biological, medical, social and economic components. Unfortunately, even experts cannot give an exact date for the end of the current pandemic. This review analyzes the impact of socio-economic and dietary factors on the development of the COVID-19 epidemic in different continents and their regions throughout 15 months. Understanding the role of factors reducing the epidemic progress should assist to find an approaching treatment to overcome the COVID-19 pandemic.

\section{Materials and methods}

For the review, required information was searched in internet using preferred keywords, which were managed as unique tags or in their various arrangements. Statistical population groups were formed from a lot of data. Most of the statistics were acquired from the following well known and reliable databanks: https://www.who.int; https://www.worldometers.info; http://www.fao.org; https://ourworldindata.org; https://databank.worldbank.org; https://www.imf.org. Rate of prevalence (RPr) or infection fatality rate (IFR) of the virus were calculated as a ratio between quantities of total cases and population. Case fatality rate (CFR) of COVID-19 is the ratio IFR/RPr in $\% \%$. The relationship between statistical data was estimated as a Pearson correlation coefficient (r).

\section{Results and discussion}

\section{Etiology and epidemic (pandemic) process of the SARS-CoV-2 virus}

Pathogenic microorganisms reside in all spheres of human environment. Viruses are obligatory cell parasites, so their life paths as a cycle between extracellular and vegetative forms. The extracellular forms are called virions and are metabolically inactive but infectious. Infection occurs when there is a sufficient concentration of virions in the habitat of a sensitive organism. After the invasion of the pathogen into the host organism, the virus replicates, damaging the infected cells and tissues, also producing a huge number of daughter virions, which are capable to infect many new sensitive objects.

Coronaviruses belong to the group of highly transmittable enveloped complex viruses disturbing acute respiratory infections in humans. The coronavirus SARS-CoV-2 is 
contagious in humans and spreads between people via respiratory droplets and mainly enters by connection to the ACE2 of the pneumocytes [13-17].

The virus SARS-CoV-2 caused the human severe acute respiratory syndrome (SARS) in China in the end of 2019. The affected infection disease was named COVID-19 by WHO [2]. The disease triggered by the virus SARS-CoV-2 can occur in an acute mild or severe respiratory form. The most common complication of the COVID-19 is pneumonia, which can lead to SARS and destruction of the lungs in a short time. The very dangerous infection disease causes the deadliest clinical manifestations. The virus is capable of infecting several different human organs, causing septic shock and multiple organ failure, thrombosis and embolism [5,18-19]. A destructive feature of the disease is severe complications like postCOVID-Syndrome called "Long-COVID", which can continue for more than a year [20-22].

\section{Epidemiological situation with coronavirus on different continents}

From 11 March 2020, when the global COVID-19 pandemic being declared [2], many infected persons have been identified in all countries and their global amount reached 175.6 mln at the 10 June 2021, in total 90.8\% from them were recovered. About 3 million 788 thousand people died from COVID-19 on this date as a consequence of the syndrome disorder [23-24]. All epidemiological data used in the review are from the study period 11 March 2020 - 10 June 2021. Analysis of statistical data from continually rising cases of infection fatality rate (IFR) and case fatality rate (CFR) through 15 months global pandemic gives practical lessons and epidemiological knowledge needed to combat the pathogen SARS-CoV-2 virus. About half of infected or died patients (Fig. 1) were from Europe and Northern America (NA). The largest number of total cases was registered in the USA, India and Brazil [23-24]. Together in these three countries were 80,764,280 infected patients, that comprises more than $45 \%$ of globally affected people [23]. On average, $2.25 \%$ of the global population was infected by SARS-CoV-2 virus, but in some European countries, above $15 \%$ of the residents were affected by this pathogen infection [23]. The highest incidence of the SARS-Cov-2 virus can exceed $80 \%$ in separated areas, where people were together in close contact with each other, while high humidity contributed to more efficient transmission of the pathogen [24]. Globally, the average mortality from COVID-19 was below $0.05 \%$ and active cases about $7 \%$ [23-24]. Rate of deaths IFR was the lowest in Asia and Africa, it matches the rate of prevalence (RPr) with correlation coefficient (r) r=0.97 (Fig. 1). Both IFR and RPr of COVID-19 vary significantly across regions and countries. For instance, in Peru or Mexico the COVID-19 CFR was above 9\%, while in the USA it was $1.79 \%$ and in Iceland $0.45 \%$ [23]. More than half of the world's pandemic deaths have been confirmed in NA and Europe (Fig. 1) [23-24], where the populations have incomes several times higher than the world average [23,25-26].

The proportion of COVID-19 mortality among the population in NA is $0.153 \%$, which was 15 times higher than in Africa (0.01\%) [23]. Due to such enormously incomparable differences in statistical data, in some publications was suggested that not all organizations provide real epidemiological facts. Large samples of statistical data are more representative, for example, information from continents or clusters of countries (Fig. 1-2).

On average in the world, roughly 22 persons from thousand were infected with the virus SARS-Cov-2 [23], with the highest prevalence ratio in Europe $(6.3 \%)$ or NA $(6.8 \%)$ and the lowest in Africa or Asia, where the proportion of the infected patients was $0.38 \%$ and $1.1 \%$, respectively (Fig. 2). It is disagreed with study in OpenSAFELY (UK secure health analytics platform) which considering, that Black and South Asian people were at higher SARS-CoV-2 risk compared with people of white ethnicity $[8,11]$. 


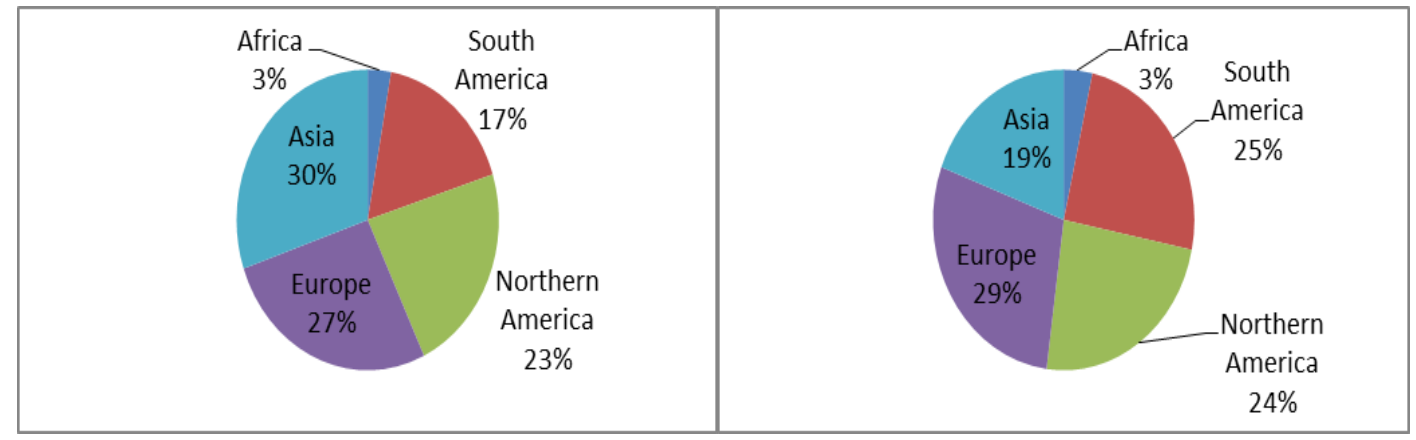

Fig. 1. The global ratio of the total number of infected or died patients

Left panel: Amount of people infected with the virus SARS-CoV-2 on five continents (10.06.2021). Oceania's share $0.04 \%$ [23].

Right panel: Proportion of deaths from COVID-19 in different continents (10.06.2021) [23].

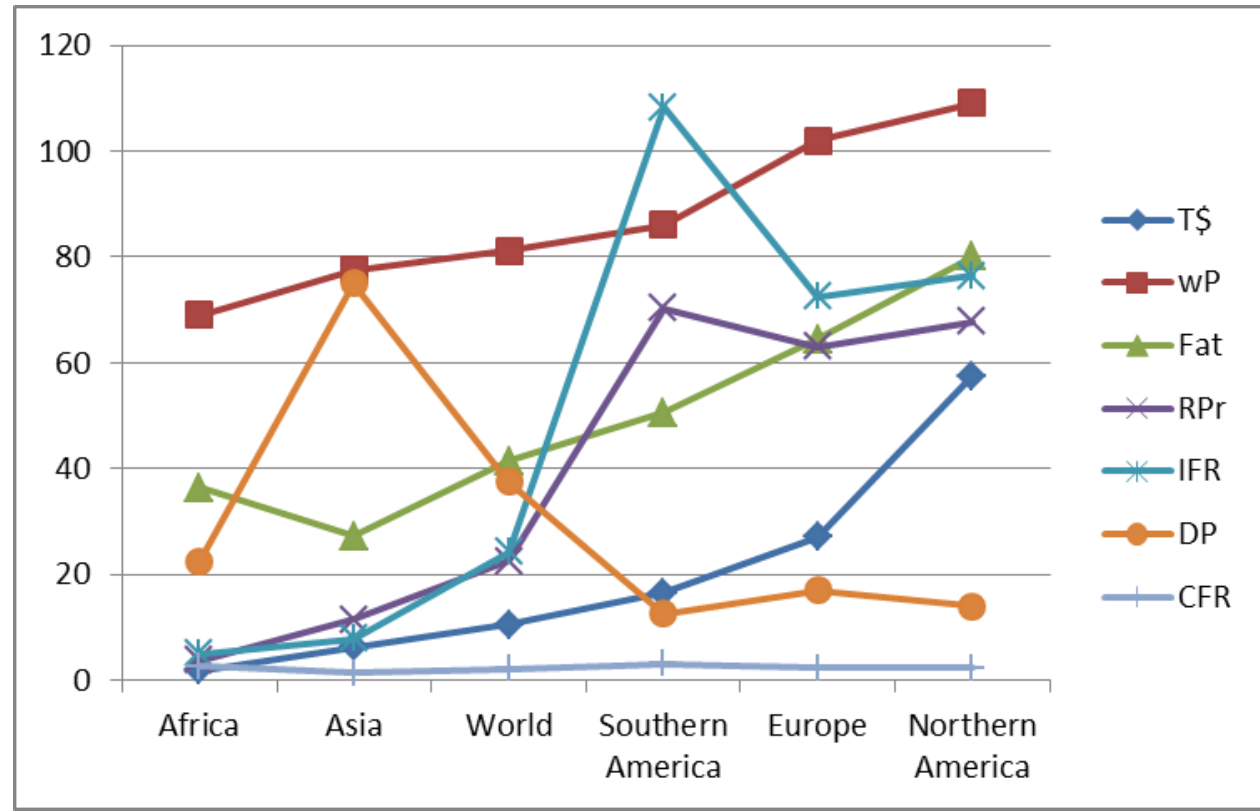

$\begin{array}{lllllll}\text { Factor } & \text { T\$ } & \text { WP } & \text { RPr } & \text { IFR } & \text { DP } & \text { CFR } \\ \text { T\$ } & & & & & & 0,06 \\ \text { WP } & 0,93 & & & & & 0,03 \\ \text { RPr } & 0,75 & \mathbf{0 , 8 4} & & & -0,66 & 0,44 \\ \text { IFR } & 0,6 & \mathbf{0 , 6 9} & 0,97 & & -0,68 & 0,59 \\ \text { Fat } & 0,94 & 0,94 & \mathbf{0 , 8 4} & \mathbf{0 , 7 1} & & 0,3\end{array}$

Fig. 2. Relation between outcomes of COVID-19 pandemic and socio-economic factors Correlation between average prevalence (RPr) [23], infection fatality rate (IFR) or case fatality rate (CFR) of the SARS-CoV-2 infection and GDP (T\$) [23,25], amount of consumed whole protein (wP) or fat (Fat) [26] and density (DP) of population [23,25]. T\$=GDP (nominal) in thousand US\$/ year/capita, $w \mathrm{P}=\mathrm{g} /$ day/person, $\mathrm{Fat}=\mathrm{g} / 2 /$ day $/$ person, $\mathrm{RPr}=$ total amount infected $/ 1000$ people (10.06.2021), IFR= total amount deaths $/ 50000$ patients $(10.06 .2021), \mathrm{CFR}=$ total amount deaths/ total amount infected in \%\%, DP=people/sq km/2.

Below are correlation coefficients (r) between COVID-19 outcomes and different factors. 
Until now, the factors of the pandemic that provide contrasting levels of resistance to the SARS-Cov-2 virus in different regions or continents during 15 months have not been studied. A comparative analysis of a huge mass of statistical data of the infectious process will allow obtain proper conclusions about the basic components and risk factors contributing to the pathogenicity of the SARS-Cov-2.

Population density $[23,25]$ with $r=0.66$ is less determining factor than the gross domestic product per capita (GDP) or diet ( $\mathrm{r}=0.84$ ) for the development of the COVID-19 epidemic calculated in continents scale (Fig. 2). There is no correlation concerning CRF of COVID-19 and amount of protein or fat consumption. Moreover it was not found any association between CRF of infection and GDP [25, 26] in continent population ( $\mathrm{r}=0.05)$. CRF depends from IRF, but not lineal (Fig. 2). Correlation between RPr and IFR is lineal with $r=0.97$, the trend line of the GDP is similar with amount of protein and fat consumption trend lines, with r $>0.8$ for continents (Fig. 2). Rate of prevalence of the COVID-19 epidemiological process correlates with fat and whole protein intake with $\mathrm{r}=0.84$ (Fig.2).

\section{SARS-CoV-2 epidemic development in island countries}

A high level of social communications is attributed in medical epidemiology to the main risk of a pandemic rising of airborne infections. Due to the high degree of urbanization, development of transport, infrastructure, education process and industrial relations, each person contacts a large number of people every day, which, in an epidemic situation, leads to an elevating of basic reproduction number (Ro) in a short time [24]. Through the process of globalization, modern society has reached a very high level of interethnic communication, which leads to a significant amount of daily contacts not only within each state, but also to a large number of intra- and inter-continental social networks.

Analyzing the development of the epidemic process in populations in which it is easy to achieve control of contacts with other countries, should allow estimate the importance of physical isolation for speed and area of virus transmission. The single island countries (sICs) group contains 8 lands according to the following principle: the territory is located on one main largest island without land borders, with a population of more than 1 million (Fig. 3). There are two exceptions to this group: Japan is an archipelago and Iceland has less than 1 million citizens. Iceland is the only island from Europe here.

These eight sICs are located in various geographic and climatic zones of the Earth, and also significantly differ in population density and the level of GDP [25,26]. It should be noted that the data in the group are highly heterogeneous across all categories, but common is that the RPr of SARS-CoV-2 infection in each country was much or even many times lower than the world or continent average (Fig. 2-3). The data on the incidence of infection and mortality in the sICs do not show a clear dependence on population density and GDP. At the same time, the level of protein or fat consumption in these countries depends on the GDP (Fig. 3) with coefficient correlation about 0.9, like in the rest of the world [26]. The RPr of the COVID-19 in sICs little related to protein and fat intake with $\mathrm{r}=0.48$ and $\mathrm{r}=0.42$. The IFR did not correlate with GDP or diet factors (Fig. 3.). In these island states, the RPr was on average $0.56 \%$, which is 4 times lower than the average in the world (Fig.2-3), which confirms the high efficiency of social isolation as a protective measure of the population against infection. However, mortality from COVID-19 can be higher in some sICs than the global average (Fig. 2-3). 
The implementation of a complex of timely control of travel contacts with the help of administrative and medical-sanitary arrangements prevented the introduction and spread of coronavirus in these island countries (Fig. 3) and in Australia [23]. WHO experts attribute high communication skills to one of the main risk factor for the COVID-19 pandemic and therefore recommend, first of all, restricting social contacts to prevent and combat the current coronavirus pandemic [24].

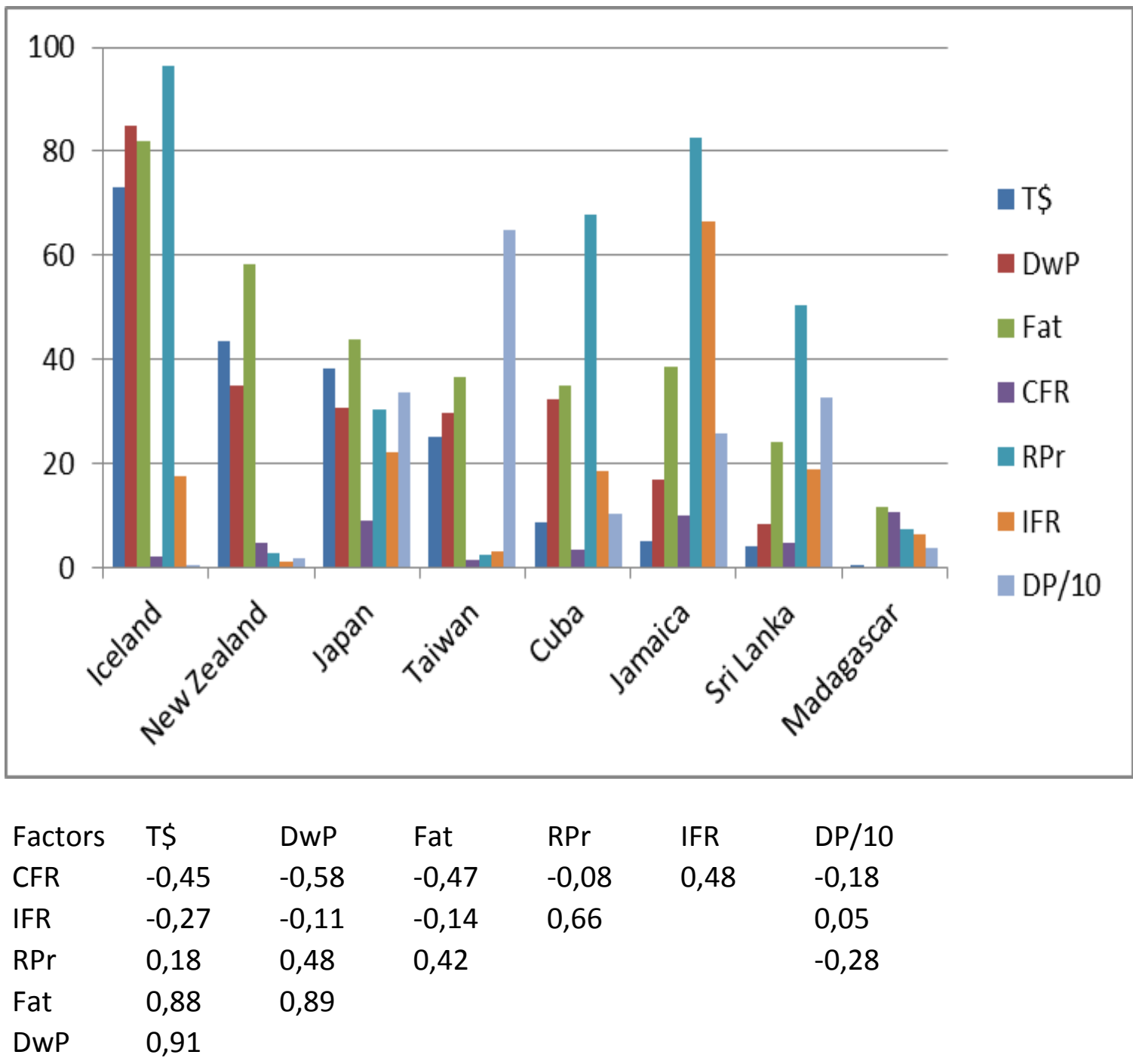

Fig. 3. Relation between COVID-19 pandemic outcomes and socio-economic factors in single island country

Correlation between average prevalence (RPr) [23], infection fatality rate (IFR) or case fatality rate (CFR) of the SARS-CoV-2 infection and GDP (T\$) [25,26], amount of consumed fat (Fat) or variation of whole protein (DwP) [26] and density (DP) of population [25,26]. T\$=GDP (nominal) in thousand $\mathrm{US} \$ /$ year/capita [26], DwP $=(\mathrm{wP}-56) \mathrm{g} /$ day/person, Fat $=\mathrm{g} / 2 /$ day/person, $\mathrm{RPr}=$ total amount infected/50 thousand people (10.06.2021), IFR= total amount deaths/200 thousand patients $(10.06 .2021), \mathrm{CFR}=\mathrm{IFR} / \mathrm{RPr}$ in $\% \%, \mathrm{DP}=$ people $/ \mathrm{sq} \mathrm{km} / 10$

Below are correlation coefficients between COVID-19 outcomes and different factors 


\section{Quantitate evaluation of socioeconomic factors and progress of virus infection}

Different categories of risks prompting of SARS-CoV-2 infection process or aggravating the course of the disease were generally analyzed by WHO and others experts [7, 9, 24, 27-34]. In the Tan and coworkers publication [33] was suggested that income disproportion in the USA associated with more infection cases and COVID-19 deaths. Recently was unpredictably found high mortality rates for well situated COVID-19 patients $[9,30]$. The same tendency for GDP was found in statistical populations of continents (Fig.2) with $r=0.75$ for prevalence and $\mathrm{r}=0.60$ for IRF.

It is generally accepted that a proper diet regulates accurate body growth and building, also provides proper metabolism reactions and furthermore enhances the body's defense mechanisms [34]. Healthy nutrition is very important and anyway mistaken or unbalanced diet can be risk factor affecting development of virus pathogenesis. Several research groups have shown that malnutrition or obesity exacerbate COVID-19 disease [35-39]. Therefore, to increase immunity in case of SARS-CoV-2 infection, an optimal diet was recommended with the inclusion of all the necessary nutritional components, trace elements and vitamins [35, 3942].

In Fig. 2 are compared numbers of total infected patients per $1 \mathrm{mln}$ and number of deaths per 50 thousand of total continent population. These numbers were very high for NA and Europe continents which included states with population owning greater income [25, 26]. As was written above, in some countries was found the association between GDP and COVID-19 death rates $[28,30,33]$. These investigations agree with presented in diagrams correlation ratio: significantly more COVID-patients have died in Europe and NA than in Asia or Africa (Fig. 1-2). In Africa and Asia the numbers of recorded cases were roughly 20 and 6 times lower than in NA [23,24]. The CRF of COVID-19 (Fig.1) were near for NA and Europe (2.26\% and 2.30\%), which were lower than in Africa (2.66\%).

If the COVID-19 prevalence and death rate (Fig. 2, 4) correlate with GDP [9, 30], therefore it is vital to find answer for the question: which component of wealthy being is the risk factor for SARS-CoV-2 infection process?

In some investigations was observed a negative relationship between COVID-19 associated death rates and using of highly recommended healthy Mediterranean diet across many countries [42-46]. In these investigations was concluded that diet can be important factor among others affecting of current corona-virus pathogenesis.

There is a correlation between GDP and amount of protein or fat in human food in numerous nations [25-26] and in different continents (Fig. 2-4). People with high GDP consume more fat and whole protein per day as recommended by WHO obligatory demand [34,47]. There are a lot of countries in Africa or in Asia with large population becoming considerably less protein or fat as recommended by WHO [26, 34, 47]. The daily intake should be 1-0,8 $\mathrm{g}$ protein or fat per kg of person per day. In some nations in NA or Europe during many decades men eat near twice more protein or fat per day as recommended by WHO [26,34]. People need adequate quantity of total protein, carbohydrates or lipids with optimal ratio from animal and plant origination, as example is recommended the Mediterranean diet [34, 40, 42]. In Africa human diet contains the lowest portion of protein or fat in the world [26, 47]. Fig. 2 shoes difference between continents in daily protein or fat intake per capita and outcomes of SARS-CoV-2 infection with tendency: less food protein composed with fat - rarely infection incidences or IRF (with $r=0,84$ and $r=0,69$ for protein or $r=0,84$ and $r=0,71$ for fat). These correlation coefficients are higher for continents than for the sICs (Fig. 2-3). 
Nutrition habits and outcomes of virus epidemic in different regions of five continents

More than a few scientific groups have investigated the effects of diet on COVID-19 disease progression and mortality in distinct nations [39,40, 42, 43, 45, 46, 48]. Kontis and coauthors [27] investigated data from the first wave of pandemic in 21 industrial countries and shown that magnitude of mortality was heterogeneous in this group of patients. In the cited publications was not compared regions highly distinguished in COVID-19 consequences besides was not discussed a correlation between amount of protein or fat intake and gravity of SARS-CoV-2 infection after the fourth wave. For this task several countries of each continent were combined into 14 groups representing regions of different continents (Table). The five clusters of regions are composed from a few neighboring countries with population similar in ethnicities, habits, traditions and eating preferences (Fig. 4).

Some intracontinental COVID-19 data from group means of RPr or IFR are deeply lower but other radically higher than continental average. It means that the epidemic outcomes differ significantly between these 14 regions (Fig. 4). Diversity in amount of total protein and fat consumption concerning the 14 regions is also very high. The RPr and IRF are less variable inside of these groups than between them (Fig. 4). Comparing epidemic statistics in regions with high and low rates should help assess risk factors for the pandemic. For that are particularly interesting to compare the states with epidemic rates more undersized than ordinary continental. These are: RUB in Europe, KUT and CLTV in Asia and BNN and ESE in Africa (Fig. 2,4). Opposite to them other regions: CPS in Europe and BNS in Africa and the USA have higher incidences and IFR than corresponding continents (Fig. 2,4). New mutants and more infection waves $[23,24]$ than at neighbors could explain the higher statistics of RPr and IFR in the USA or CPS regions and statistical outlier for South America (Fig. 2). People from three states included in the 14 groups: Austria, France and the USA consume the highest amount of protein 108-113 g and fat 159-166 g per day per person and comprise correspondingly RPr 72-103 [23] and IFR 1.2-1.8 per one thousand population, which are greater than average ones in all continents (Fig. 2-4).

Populations in RUB region eat less whole protein or fat than around Europe showing lower $\mathrm{RPr}=39$ and IFR=0.9 (per thousand people), comparing with Europe mean $\mathrm{RPr}=63$ and IFR=1,4 (Fig. 2,4). Ingesting of fat in Asia is fewer and in NA twice more than WHO recommended $[34,47]$. Overconsuming of protein in the USA is more than twofold higher than in Asia (Fig. 2,4). The consequences of epidemic in Asia were less dramatic as in NA with contrary rates $\mathrm{RPr}=11.4$ or $\mathrm{RPr}=67.7$ and IFR=0.16 or IFR=1.5 (Fig. 2.). 
Table. Regions of different countries from five continents

\begin{tabular}{l|l|} 
Region & Country \\
\hline East Part of & Benin \\
\hline West Africa & Niger \\
& Nigeria \\
\cline { 2 - 2 } & BNN
\end{tabular}

\begin{tabular}{l|l|} 
Region & Country \\
Central & Czechia \\
\hline Europe & Poland \\
& Slovakia \\
& CPS
\end{tabular}

\begin{tabular}{l|l|}
\multirow{4}{*}{$\begin{array}{l}\text { North Nile } \\
\text { region }\end{array}$} & Egipt \\
\hline & Ethiopia \\
\hline & Sudan \\
\hline & ESE \\
\hline $\begin{array}{l}\text { Southern } \\
\text { Africa }\end{array}$ & Botswana \\
& $\begin{array}{l}\text { South } \\
\text { Africa }\end{array}$ \\
& BNS \\
\hline
\end{tabular}

\begin{tabular}{l|l|}
\begin{tabular}{l|l|} 
Mediter- \\
ranean \\
Europe
\end{tabular} & Spain \\
& Italy \\
& Portugal \\
& SIP \\
\hline $\begin{array}{l}\text { Eastern } \\
\text { Europe }\end{array}$ & Russia \\
& Ukraine \\
& Relarus \\
\hline &
\end{tabular}

\begin{tabular}{|l|l|} 
Region & Country \\
\hline \multirow{3}{*}{ South Asia } & Bangladesh \\
& India \\
\hline & Nepal \\
\hline & Pakistan \\
\hline
\end{tabular}

\section{BINP}

\begin{tabular}{l|l|}
\hline & Austria \\
\hline \multirow{3}{*}{$\begin{array}{l}\text { Western } \\
\text { Europe }\end{array}$} & Belgium \\
& France \\
& Germany \\
& Netherlands \\
& Switzerland \\
\hline & WE
\end{tabular}

\begin{tabular}{l|l|}
\hline \multirow{3}{*}{$\begin{array}{l}\text { Mainland } \\
\text { South-Estern } \\
\text { Asia }\end{array}$} & Cambodia \\
\cline { 2 - 2 } & Laos \\
\hline & Thailand \\
\hline & Vietnam \\
\hline & CLTV
\end{tabular}

\begin{tabular}{l|l|} 
& \\
\hline \begin{tabular}{l|l} 
Maritimeland \\
South-estern
\end{tabular} & Malaysia \\
Asia & Indonesia \\
\cline { 2 - 2 } & Philippines \\
\hline
\end{tabular}

\begin{tabular}{|l|l|}
\hline \multirow{2}{*}{ Central Asia } & Kyrgyzstan \\
& Uzbekistan \\
\hline & Tajikistan \\
\hline & KUT
\end{tabular}

KUT

NA

USA

\begin{tabular}{l|l|}
\begin{tabular}{l|l|} 
Region \\
North-West \\
of Southern
\end{tabular} & Country \\
\cline { 2 - 2 } America & Bolivia \\
\hline & Brasil \\
\hline
\end{tabular}

BBP

South-East of Southern

America

Colombia

Ecuador

Peru

CEP 


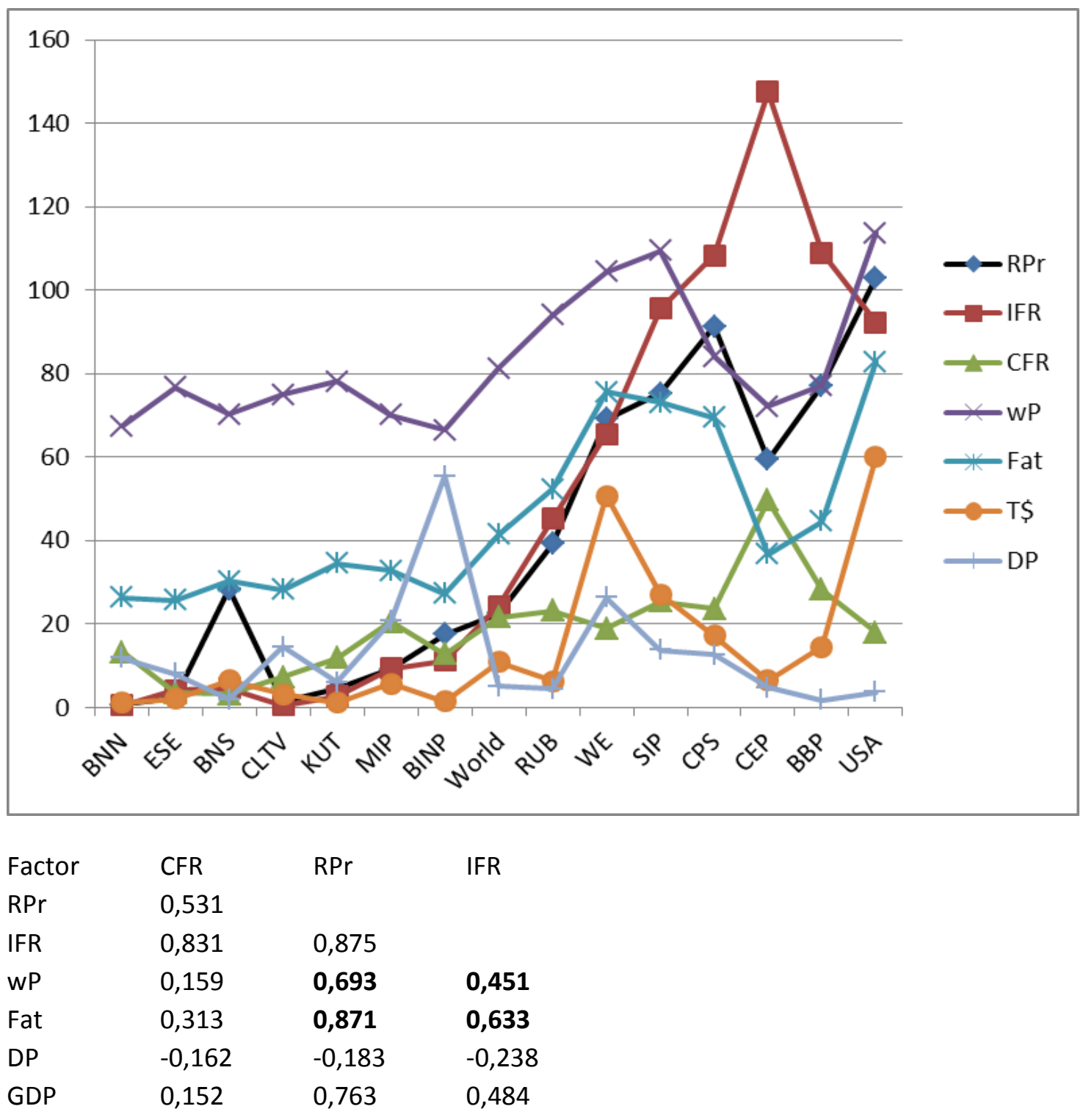

Fig. 4. Relation between pandemic outcomes of COVID-19 and diet factors in 14 regions Correlation between average prevalence (RPr) [23], infection fatality rate (IFR) or case fatality rate (CFR) of the SARS-CoV-2 infection and amount of consumed whole protein (wP) or fat (Fat) [26]. $\mathrm{RPr}=$ total amount infected $/ 1000$ people, IFR $=$ total amount deaths $/ 20000$ patients, $\mathrm{CFR}=$ total amount deaths/ total amount infected in $\% \%, w \mathrm{P}=\mathrm{g} /$ day/person, Fat $=\mathrm{g} / 2 /$ day $/$ person Below are correlation coefficients between COVID-19 outcomes and different factors

The region of South-East Asia has shown the world minimal amounts of infection and mortality cases. The rates in Laos or Vietnam of group CLTV were minimal, such as RPr 0.27 or 0.10 per thousand and IFR 0.4 or 0.6 per million people [23]. These communities have a meal with $90 \mathrm{~g}$ protein/day/person in Vietnam or $83 \mathrm{~g}$ protein/day/person in Laos, which are higher than recommended by WHO [26, 34, 47]. Society in this two states consumes in Laos fat $49 \mathrm{~g} /$ day/person or 79 in Vietnam [26,34]. However, in the CLTV region, the incidence rates and mortality from COVID-19 were absolute minimal (Fig. 4), although people here consume more protein than in other regions of South- or East-Asia, where the frequency of infection incidences was significantly upper (Fig. 4). A feature of the territorial diet in CLTV 
region is the highest consumption of soybean products. The world average consumption of soy protein is $0.77 \mathrm{~g}$ per day per person [47]. The main consumers of soybeans are residents of China, South- and South-East Asia. One consumer in Cambodia ingests an average of 4.42 $\mathrm{g}$, and in Vietnam $9.14 \mathrm{~g}$ of soy protein per day [47]. In Japan and Taiwan, the intake of soy products is almost an order of magnitude higher than the world median: 8.23 and $8.70 \mathrm{~g}$ of protein per capita per day [47]. The three nations: Vietnam, Taiwan and Japan with greatest soy supply per capita have largely higher than mean Asian (Fig.2) population density (314, 673 and 347 people/ sq km [25,26]) and coupled with RPr [23] and IFR, which are much low than in neighboring states (Fig. 4).

African nations generally eat much less soy products than in Asia [47]. In African regions BNN and ESE the consumption of total protein or fat was lower than the world average, and at the same time, the frequency of infections was an order of magnitude lower. In West Africa region BNN was COVID-19 weaker than in other territories of Africa with $\mathrm{RPr}=0.55$ and $\mathrm{IFR}=0,01$ (Fig. 4). Average consumption is $67 \mathrm{~g}$ protein/day/person and $53 \mathrm{~g}$ fat/day/person in the BNN group. For example, in West Africa region BNN was COVID-19 weaker than in other territories of Africa with $\mathrm{RPr}=0.55$ and IFR=0,01 (Fig. 4). Average consumption is $67 \mathrm{~g}$ protein/day/person and $53 \mathrm{~g}$ fat/day/person in the BNN group. The CFR is in Africa much higher than in the USA or regions of Asia (Fig. 2, 4), which, first of all, should be associated with the level of medical care. The CFR depends from IFR more efficient than from GDP (Fig. 2,4.).

Africa and Asia have very low epidemic data with intake of the whole protein in range 67-78 g/day/capita and fat 53-73 g/day/capita (Fig. 2.). Easy-going outcomes of COVID-19 are in regions (Fig. 4) with consumption of protein or fat in amount near recommended by WHO $[23,26,34,47]$.

The negative impact of excessive diet protein or fat on the infectious process of SARS-CoV-2 found for populations of five continents is also manifested for nations of 45 countries combined in 14 different regions of these continents (Fig. 2,4). Correlation between infection prevalence and amount of protein or fat consumption around 14 regions shows $r=0.69$ or $\mathrm{r}=0.87$. These coefficients for IRF are 0.45 and 0.63 , which are smaller than the continent rates (Fig. 2,4)

The number of diseases and mortalities from COVID-19 has undulating increased and achieved in 15 months, on 10 June 2021, respectively around 175 and 3.8 million [23,24]. Currently, many thousand results of various studies of medical epidemiology on the coronavirus SARS-CoV-2 and induced disease have been published in the Internet, and the risk factors for the infection that caused the pandemic and the technologies to overcome it are also being intensively studied. It is undeniable that timely and reliable isolation from sources of infection prevents an epidemic of any transmissible pathogen, including virus SARS-CoV2 (Fig. 3). The high quality of medical service ensures effective treatment of patients and reduces mortality. The influence of these two factors, as well as vaccination, has been demonstrated in a huge number of studies on pathogen invasion and dynamic of the infection disease of the different viruses. These three factors are essential in practical strategy model to prevent virus epidemic or pandemic.

Analysis of statistical data on the development of infection SARS-CoV-2 in different continents and 14 regions of these continents showed huge variability in morbidity and mortality (Fig. 2-4). The total number of the COVID-19 patients and victims of the epidemic in different continents vary significantly and can differ by almost 20 times if we compare these data for NA and Africa (Fig. 1-2). 
In many publications, researchers discuss a number of potential factors that can influence the infectious process of the coronavirus or the course of COVID-19 disease. Despite the huge amount of broad and high-tech research, so far, no direct factors have been presented that could reduce any infectious process as affectionately as the three above.

Until now, no factors have been identified which could explain a significant difference in the prevalence and deaths from SARS-CoV-2 infection in different regions or continents. Figures 2 and 4 present that population from regions with high income where protein and fat consumption per capita is considerably greater than the WHO recommends have the highest number of infections and the highest death rate from COVID-19 per one million [23]. Asia and Europe have the largest number of total reported carriers of the virus (Fig.1), while NA and South America have the highest number of deaths per million inhabitants [23]. In America and Europe, people eat obviously more fat and protein than in Asia or Africa. In East-Asian countries, mass consumption of soybeans correlates with extremely mild manifestations of COVID-19 (Fig.4.). However, the phenomenon of resistance of populations with a low-protein diet or high consumption of soy products against SARS-CoV-2 infection remains to be studied.

\section{Conclusions}

In this review was analyzed the impact of geographic isolation, population density, GDP and amount of staple food consumption on the development of the epidemic process of SARSCoV-2 during 15 months in statistical populations representing residents of five continents split in 14 groups from 45 lands and from 8 island countries (Fig. 1-4). Objective, adequate total protein and fat intake coincides with appropriate low rates of coronavirus SARS-CoV-2 pathogenic infection outcomes (Fig.2,4). The development of the epidemic process does not correlate with the population density in sICs, in group of regions, but slightly in big populations (Fig. 2-4).

The factor of nation isolation from the spread of infection is primary preventive, as it avoids contact between the organism and the pathogen. Diet cannot affect the transmission of virions, but after the introduction of virus into the body, the influence of nutritional components on the destructive biochemical reactions of the pathogen in the host's body is very possible. According to the prediction of WHO experts, this pandemic would last at least two-three years, but it is difficult to forecast the exact end date. In this review was concluded a model, that overconsuming of protein and fat may be a risk factor for COVID-19 (Fig. 2,4). However, a suggestion emerges from this review is: try to reduce the global and personal damage from the COVID-19 epidemic by changing the diet, which is easy and cheap to implement. The economy model to combat virus infection is important in the situation where no new specific methods have been proved to defeat the pandemic of the COVID-19. 


\section{References}

1. WHO What is a pandemic? https://www.who.int/csr/disease/ Accessed: 20.07.2021

2. WHO Director-General's opening remarks at the media briefing on COVID-19 - 11

March 2020. Available at: https://www.who.int/director-general/speeches/detail/whodirector-general-s-opening-remarks-at-the-media-briefing-on-covid-19---11-march-2020.

Accessed: 20.07.2021

3. Liu, X. X., Fong, S. J., Dey, N., et al. A new SEAIRD pandemic prediction model with clinical and epidemiological data analysis on COVID-19 outbreak. Applied Intelligence, 2021: 1-37. https://doi.org/10.1007/s10489-020-01938-3

4. Plazas A., Malvestio I., Starnini M., et al. Modeling partial lockdowns in multiplex networks using partition strategies. Appl Netw Sci. 2021; 6 (27): 1-15. https://doi.org/10.1007/s41109-021-00366-7

5. Cascella M., Rajnik M., Aleem A., et al. R. Features, Evaluation, and Treatment of Coronavirus (COVID-19). COVID-19 Information. Available at:

https://www.ncbi.nlm.nih.gov/books/NBK554776/\#article-52171.s2 Accessed: 20.07.2021

6. Disparities in the risk and outcomes of COVID-19. Available at:

https://assets.publishing. service.gov.uk/government/uploads/

system/uploads/attachment_data/file/908434/ Accessed: 20.07.2021

7. Jin, J., Agarwala, N., Kundu, P. et al. Individual and community-level risk for COVID19 mortality in the United States. Nat Med. 2021; 27: 264-269.

https://doi.org/10.1038/s41591-020-01191-8

8. Mathur R., Rentsch C.T., Morton C.E., et al. OpenSAFELY Collaborative. Ethnic differences in SARS-CoV-2 infection and COVID-19-related hospitalisation, intensive care unit admission, and death in 17 million adults in England: an observational cohort study using the OpenSAFELY platform. Lancet. 2021; 397(10286):1711-1724. https://doi: 10.1016/S0140-6736(21)00634-6.

9. Roy S, Ghosh P. Factors affecting COVID-19 infected and death rates inform lockdown-related policymaking. PLoS One. 2020;15(10):e0241165.

https://doi:10.1371/journal.pone.0241165. Accessed: 20.07.2021

10. Van Damme W, Dahake R, Delamou A, et al. The COVID-19 pandemic: diverse contexts; different epidemics-how and why? BMJ Glob Health. 2020; 5(7) :e003098. https://doi: 10.1136/bmjgh-2020-003098. Accessed: 20.07.2021

11. Williamson E.J., Walker, A.J., Bhaskaran, K. et al. Factors associated with COVID-19related death using OpenSAFELY. Nature. 2020; 584: 430-436.

https://doi.org/10.1038/s41586-020-2521-4_N2020

12. Zhang W, Zhang C, Bi Y, Yuan L, et al. Analysis of COVID-19 epidemic and clinical risk factors of patients under epidemiological Markov model. Results Phys. 2021; 22 :103881. https://doi: 10.1016/j.rinp.2021.103881. Accessed: 20.07.2021

13. Hu B., Guo H., Zhou P. et al. Characteristics of SARS-CoV-2 and COVID-19. Nat Rev Microbiol. 2021; 19: 141-154. https://doi.org/10.1038/s41579-020-00459-7

14. To K. K., Sridhar S., Chiu K. H., et al. Lessons learned 1 year after SARS-CoV-2 emergence leading to COVID-19 pandemic. Emerging microbes \& infections. 2021; 10(1): 507-535. https://doi.org/10.1080/22221751.2021.1898291

15. Hoffmann M, Kleine-Weber H, Schroeder S, et al. SARS-CoV-2 Cell Entry Depends on ACE2 and TMPRSS2 and Is Blocked by a Clinically Proven Protease Inhibitor. Cell. 2020; 181(2) :271-280. e8. https://doi: 10.1016/j.cell.2020.02.052. 
16. Lan, J., Ge, J., Yu, J. et al. Structure of the SARS-CoV-2 spike receptor-binding domain bound to the ACE2 receptor. Nature. 2020; 581: 215-220. https://doi.org/10.1038/s41586020-2180-5

17. Wu S.-C., Arthur C.M., Jianmei Wang J., et al. The SARS-CoV-2 receptor-binding domain preferentially recognizes blood group A. Blood Adv. 2021; 5 (5): 1305-1309. https://doi.org/10.1182/bloodadvances.2020003259

18. Mokhtari T, Hassani F, Ghaffari N, et al. COVID-19 and multiorgan failure: A narrative review on potential mechanisms. J Mol Histol. 2020; 51(6): 613-628. https://doi:

10.1007/s10735-020-09915-3.

19. Kordzadeh-Kermani E, Khalili H, Karimzadeh I. Pathogenesis, clinical manifestations and complications of coronavirus disease 2019 (COVID-19). Future

Microbiol. 2020; 15 :1287-1305. https://doi: 10.2217/fmb-2020-0110.

20. Al-Aly, Z., Xie, Y. \& Bowe, B. High-dimensional characterization of post-acute sequelae of COVID-19. Nature. 2021. https://doi.org/10.1038/s41586-021-03553-9

Accessed: 20.07.2021

21. COVID-19 rapid guideline: managing the long-term effects of COVID-19 NICE guideline [NG188] Published: 18 December 2020. Available at:

https://www.nice.org.uk/guidance/NG188 Accessed: 20.07.2021

22. Sudre CH, Murray B, Varsavsky T, et al. Attributes and predictors of long COVID. Nat Med. 2021; (4): 626-631. https://doi: 10.1038/s41591-021-01292-y.

23. https://www.worldometers.info Accessed: 20.07.2021

24. https://www.who.int/emergencies/diseases/novel-coronavirus-2019 Accessed: 20.07.2021

25. data.worldbank.org/ Accessed: 20.07.2021

26. https://ourworldindata.org/food-supply Accessed: 20.07.2021

27. Kontis V., Bennett J.E., Rashid T., et al. Magnitude, demographics and dynamics of the effect of the first wave of the COVID-19 pandemic on all-cause mortality in 21

industrialized countries. Nat. Med. 2020; 26: 1919-1928. https://doi.org/10.1038/s41591020-1112-0

28. Amaratunga, D., Cabrera, J., Ghosh, D. et al. Socio-economic impact on COVID-19 cases and deaths and its evolution in New Jersey. Ann Oper Res. 2021.

https://doi.org/10.1007/s10479-021-03941-4 Accessed: 20.07.2021

29. Du P., Li D., Wang A., et al. A Systematic Review and Meta-Analysis of Risk Factors Associated with Severity and Death in COVID-19 Patients. Can. J. Infect. Dis. Med.

Microbiol. 2021; Article ID 6660930: 12 pages. https://doi.org/10.1155/2021/6660930

Accessed: 20.07.2021

30. Hashim M.J., Alsuwaidi A.R., Khan G. Population Risk Factors for COVID-19

Mortality in 93 Countries. J Epidemiol Glob Health. 2020; 10(3): 204-208.

https://doi:10.2991/jegh.k.200721.001.

31. People with Certain Medical Conditions. Available at:

https://www.cdc.gov/coronavirus/ 2019-ncov/need-extra-precautions/people-with-medicalconditions.html Accessed: 20.07.2021

32. Siegel, M., Critchfield-Jain, I., Boykin, M. et al. Actual Racial/Ethnic Disparities in COVID-19 Mortality for the Non-Hispanic Black Compared to Non-Hispanic White Population in 35 US States and Their Association with Structural Racism. J. Racial and Ethnic Health Disparities. 2021. https://doi.org/10.1007/s40615-021-01028-1 Accessed: 20.07.2021 
33. Tan A.X., Hinman J.A., Abdel Magid H.S., et al. Association Between Income Inequality and County-Level COVID-19 Cases and Deaths in the US. JAMA Netw Open. 2021;4(5):e218799. https://doi:10.1001/jamanetworkopen.2021.8799 Accessed: 20.07.2021

34. Joint WHO/FAO/UNU Expert Consultation. Protein and amino acid requirements in human nutrition. World Health Organ Tech Rep Ser. 2007; 935: 1-265. PMID: 18330140 35. Ali A.M., Kunugi H. Approaches to Nutritional Screening in Patients with Coronavirus Disease 2019 (COVID-19). Int. J. Environ. Res. Public Health. 2021; 18: 2772. https://doi.org/10.3390/ijerph18052772

36. Allard L., Ouedraogo E., Molleville J., et al. Malnutrition: Percentage and Association with Prognosis in Patients Hospitalized for Coronavirus Disease 2019. Nutrients. 2020; 12(12): 3679. https://doi: 10.3390/nu12123679.

37. Hu X., Deng H., Wang Y., Chen L, et al. Predictive value of the prognostic nutritional index for the severity of coronavirus disease 2019. Nutrition. 2021; 84: 111123. https://doi: 10.1016/j.nut.2020.111123. Accessed: 20.07.2021

38. Rothenberg E. Coronavirus Disease 19 from the Perspective of Ageing with Focus on Nutritional Status and Nutrition Management-A Narrative Review. Nutrients. 2021; 13(4): 1294. https://doi: 10.3390/nu13041294.

39. Sahin E., Orhan C., Uckun F.M., et al. Clinical Impact Potential of Supplemental Nutrients as Adjuncts of Therapy in High-Risk COVID-19 for Obese Patients. Front Nutr. 2020; 7: 580504. https://doi: 10.3389/fnut.2020.580504. Accessed: 20.07.2021

40. Akhtar S., Das J. K., Ismail T., et al. 2021). Nutritional perspectives for the prevention and mitigation of COVID-19. Nutrition reviews. 2021; 79(3): 289-300.

https://doi.org/10.1093/nutrit/nuaa063

41. Eating healthy before, during and after COVID-19. Available at:

http://www.fao.org/fao-stories/article/en/c/1392499/ Accessed: 20.07.2021

42. Perez-Araluce R., Martinez-Gonzalez M.A., Fernández-Lázaro C.I., et al.

Mediterranean diet and the risk of COVID-19 in the 'Seguimiento Universidad de Navarra' cohort. Clin Nutr. 2021; 15: S0261-5614(21)00190-4. https://doi:

10.1016/j.clnu.2021.04.001. Accessed: 20.07.2021

43. Bousquet, J., Anto, J.M., Iaccarino, G. et al. Is diet partly responsible for differences in COVID-19 death rates between and within countries?. Clin Transl Allergy. 2020; 10: 16. https://doi: 10.1186/s13601-020-00323-0.

44. Davis C., Bryan J., Hodgson J., Murphy K. Definition of the Mediterranean Diet; a Literature Review. Nutrients. 2015; 7(11): 9139-53. https://doi: 10.3390/nu7115459.

45. Greene M.W., Roberts A.P., Frugé A.D. Negative Association Between Mediterranean Diet Adherence and COVID-19 Cases and Related Deaths in Spain and 23 OECD

Countries: An Ecological Study. Front Nutr. 2021; 8: 591964. https://doi:

10.3389/fnut.2021.591964. Accessed: 20.07.2021

46. Tuttolomondo A., Simonetta I., Daidone M., et al. Metabolic and Vascular Effect of the Mediterranean Diet. Int J Mol Sci. 2019; 20(19): 4716. https://doi: 10.3390/ijms20194716. 47. New Food Balances. Available at: https://FAO.org/faostat/en/\#data/FBS Accessed:

20.07.2021 